\title{
Genetic Analyses of Kernel Carotenoids in Novel Maize Genotypes Possessing Rare Allele of $\beta$-carotene hydroxylase Gene
}

\author{
V. Muthusamy ${ }^{1}$, F. Hossain ${ }^{1}$, N. ThirunavukKarasu ${ }^{1}$, S. Saha ${ }^{1}$, \\ P.K. AGRAWAL ${ }^{2,3}$ and H.S. GUPTA ${ }^{1,4 *}$ \\ ${ }^{1}$ ICAR-Indian Agricultural Research Institute (IARI), New Delhi, India \\ ${ }^{2}$ ICAR-Vivekanand Parvatiya Krishi Anusandhan Sansthan (VPKAS), Almora, India \\ ${ }^{3}$ Present Address: Krishi Anusandhan Bhawan-I, ICAR, New Delhi, India \\ ${ }^{4}$ Present Address: Borlaug Institute for South Asia (BISA), New Delhi, India
}

(Received 26 March 2016; Accepted 27 April 2016;

Communicated by T. Harangozó)

\begin{abstract}
Carotenoids are important micronutrients required by humans for growth and development. Yellow maize among cereals possesses sufficient carotenoids, and thus, it is important to genetically dissect such traits for proper utilization in breeding programme. Twenty-one maize hybrids generated using novel inbreds with rare allele of $\beta$-carotene hydroxylase (crtRB1) that enhances kernel $\beta$-carotene, were evaluated at two diverse maize growing locations. Lutein, zeaxanthin and $\beta$-cryptoxanthin were positively correlated, while $\beta$-carotene showed negative correlation with other carotenoids. Grain yield did not show association with carotenoids. Preponderance of additive gene action was observed for lutein, zeaxanthin, $\beta$-cryptoxanthin and $\beta$-carotene. Experimental hybrids were much superior for kernel $\beta$-carotene compared to commercial hybrids. Based on SCA effects, high yielding experimental hybrids were identified for provitamin A and non-provitamin A carotenoids. These novel hybrid combinations of maize possessing rare allele of $\operatorname{crtRB} 1$ hold promise in maize biofortification programme to alleviate vitamin A deficiency and degenerative diseases in humans.
\end{abstract}

Keywords: biofortification, crtRB1, carotenoids, combining ability, Zea mays

\section{Introduction}

Carotenoids play vital role in human metabolism and are essential for adequate growth and development. Among different carotenoid fractions, $\alpha$-carotene, $\beta$-carotene and $\beta$-cryptoxanthin serve as the precursor for vitamin A biosynthesis, while lutein and zeaxanthin act as scavengers for free radicals (Olson 1989). Vitamin A or retinol is required for normal functioning of the visual system, growth and development, maintenance of epithelial cell integrity, immune system and reproduction (Burri 1997). Non-provitamin A carotenoids such as lutein and zeaxanthin serve as dietary antioxidants in humans and reduce the risk of degenerative diseases (Fraser and Bramley 2004). Vitamin A deficiency

*Corresponding author; E-mail: hsgupta.53@gmail.com 
(VAD) results in visual impairment and mortality in at least 190 million pre-school children and 19 million pregnant women, mostly in Africa and South Asia (Gupta et al. 2015). It also causes low resistance to infectious diseases and accounts for about $70 \%$ of childhood deaths across the world. Cardiovascular diseases have emerged as one of the leading causes of deaths worldwide and the intake of antioxidant-rich food reduces the risk of cardiovascular disease in humans (Dauchet et al. 2009). Humans and animals are unable to anabolize these carotenoids; therefore, they are required to be provided through dietary means. Thus, efforts directed to enrich staple food with specific carotenoids will have a significant impact on the health of humans particularly, women and children (Bouis et al. 2011).

Development of micronutrient-enriched staple plant foods through plant breeding, referred to as 'biofortification' holds immense promise for sustainable food-based solutions to alleviate hidden hunger (Gupta et al. 2015). Biofortification is more sustainable and cost-efficient compared with the nutrition interventions such as 'supplementation', 'food fortification', and 'dietary diversification' (Bouis et al. 2011). Among cereals, only the yellow kernel maize possesses significant levels of carotenoids, thereby showing potential for biofortification through breeding (Buckner et al. 1990). In traditional maize genotypes, $\beta$-carotene and $\beta$-cryptoxanthin possessing provitamin A activity are present in minor fraction, while non-provitamin A carotenoids, viz. zeaxanthin and lutein are the predominant fraction (Vignesh et al. 2012; Muthusamy et al. 2015a, 2015b).

Among various genes in the carotenoid biosynthesis pathway, crtRB1 ( $\beta$-carotene hydroxylase) is primarily responsible for enhanced accumulation of $\beta$-carotene concentration in maize kernels (Yan et al. 2010; Muthusamy et al. 2014). A rare natural mutant possessing polymorphism (transposable element) at 3' end of the $\operatorname{crtRB} 1$ gene is reported to have two- to tenfolds higher $\beta$-carotene accumulation in the endosperm than the unfavourable allele (Yan et al. 2010). Maize inbreds with high $\beta$-carotene have been developed under the CIMMYT-HarvestPlus programme with the crtRB1-favourable allele (Babu et al. 2013). Large-scale screening of Indian maize germplasm has led to identification of inbred lines with favourable allele of crtRB1 (Muthusamy et al. 2015c). The allele has been found to be present in extremely low frequency, thus the inbreds with favourable-crtRB1 allele are novel possessing great promise in maize biofortification programme (Choudhary et al. 2015).

Estimation of combining ability and nature of gene action using suitable mating design will help the breeder to assess the performance of a genotype as a parent in crosses, devise a suitable breeding strategy and to identify the best hybrid combinations with higher heterosis (Zunjare et al. 2015). Information on combining ability and nature of gene action for kernel carotenoids in maize are limited and those involved traditional maize germplasm mainly adapted to US and Brazil (Egesel et al. 2003; Senete et al. 2011). Suwarno et al. (2014) have undertaken genetic analyses of carotenoids among maize inbreds possessing favourable allele of $\operatorname{crtRB} 1$. To our knowledge, this is the only report available that exploited these unique inbreds in the breeding programme. However, the study involved only the inbreds developed under the CIMMYT-HarvestPlus programme. In the present investigation, we intended to dissect the trait by involving diverse $\operatorname{crtRB} 1$-based 
inbreds of exotic- (bred by CIMMYT-HarvestPlus) and indigenous- (identified in Indian maize breeding programme) origin with a view to: (i) assess the combining ability and nature of gene action for kernel carotenoids; and (ii) identify superior hybrid combinations for specific carotenoids over commercially available hybrids.

\section{Materials and Methods}

Generation of experimental crosses

A $7 \times 3$ (line $\times$ tester) mating design set comprising of Indian inbreds as 'line' (Pant120, MGU150-1, MGU150-3, MGUDM-RIL47, Pant125, HP233-20 and SE547) and CIMMYT-HarvestPlus inbreds as 'tester' (HP467-9, HP465-20 and HP467-4) was generated during winter 2010-11 at Maize Winter Nursery Centre, ICAR-Indian Institute of Maize Research (IIMR) Hyderabad. All the inbreds possessed the favourable allele of crtRBI gene (with 3'TE polymorphism).

\section{Evaluation of the experimental crosses and their parental inbreds}

The line $\times$ tester set, comprising 10 parents, their $21 \mathrm{~F}_{1}$ generations and four commercial hybrids as controls (HM-9, HM-11, HQPM-5 and JH-3459) were evaluated at two diverse locations of India, viz. (i) IARI experimental farm, New Delhi $\left(28^{\circ} 08^{\prime} \mathrm{N}, 177^{\circ} 12^{\prime}\right.$ E and $229 \mathrm{~m} \mathrm{ASL}$ ) and (ii) Hawalbagh farm, VPKAS, Almora, Uttarakhand $\left(29^{\circ} 35^{\prime} \mathrm{N}\right.$, $79^{\circ} 39^{\prime} \mathrm{E}$ and $1250 \mathrm{~m}$ ASL) during rainy season of 2011.

The genotypes were planted in a randomized complete block design (RCBD) with two replications per entry and one row per replication and with a plant-to-plant spacing of 25 $\mathrm{cm}$ and row-to-row spacing of $75 \mathrm{~cm}$. Standard agronomic practices were followed for raising and maintenance of the plants. In each plot, a uniform plant stand of 15 plants was maintained by thinning. Five plants in each of the replication were self-pollinated to avoid any xenia effect caused due to fertilization by foreign pollen. Self-pollinated ears from each entry were harvested separately; seeds were shelled under shade and stored at $4{ }^{\circ} \mathrm{C}$ until carotenoid extraction. The cobs from open pollinated ears were harvested for measuring the grain yield.

\section{Extraction and quantification of various carotenoid components}

Carotenoid extraction from maize kernel was carried out using the procedure described by Kurilich and Juvick (1999) with minor modifications. Quantification of the carotenoids was carried out with a Water Alliance HPLC system (High Performance Liquid Chromatography, Waters Chromatography, Milford, MA) attached with a photodiode array detector (PDA). The HPLC components include e2695 separation module and the 2996 PDA detector and the system was operated with Empower 2 Software (Waters Corporation). A $20 \mu \mathrm{l}$ volume of each sample was manually injected into the HPLC system and were eluted through YMC Carotenoid C30 column $(5 \mu \mathrm{m}, 4.6 \times 250 \mathrm{~mm}$; YMC, 
Waters) and detected with PDA. The mobile phase consisted of methanol: tert-butyl methyl ether (80:20), and the flow rate was $1 \mathrm{ml} \mathrm{min}{ }^{-1}$. The $\beta$-carotene, $\beta$-cryptoxanthin, lutein and zeaxanthin peaks were detected at $450 \mathrm{~nm}$ with $1.2 \mathrm{~nm}$ wavelength resolutions. Six dilutions of each carotenoid standard (SIGMA Chemicals, USA) were used to make the standard curve and the concentration of various carotenoids in sample was estimated by standard regression method.

\section{Statistical analysis}

Combining ability analysis (with fixed model) for kernel carotenoids was carried out using WINDOSTAT 8.5. Mean data across locations were used to estimate the Pearson's correlation coefficient among different carotenoids. Fold change for carotenoids was calculated by dividing the value in experimental hybrids over commercial checks.

\section{Results}

Combined analysis of variance (ANOVA) revealed that location did not show any effects on zeaxanthin, $\beta$-cryptoxanthin and $\beta$-carotene except for lutein (Table 1). Significance of mean square due to crosses, lines, and line $\times$ tester were observed for all the carotenoid components. Among carotenoids, lutein, zeaxanthin and $\beta$-cryptoxanthin did not show location $\times$ cross interaction, whereas $\beta$-carotene showed significant effect for the same but with low magnitude $(0.05 \%)$ (Table 1$)$. The narrow sense heritability was high for lutein $(71.0 \%)$, zeaxanthin $(66.7 \%)$ and $\beta$-cryptoxanthin $(73.9 \%)$, while it was of moderate degree for $\beta$-carotene (48.7\%) (Table 1$)$.

Average concentration among the lines for lutein and zeaxanthin were 5.4 and $7.7 \mu \mathrm{g}$ $\mathrm{g}^{-1}$, respectively (Table 2). The same among the testers was much lower, i.e. $0.7 \mu \mathrm{g} \mathrm{g}^{-1}$ of lutein and $1.5 \mu \mathrm{g} \mathrm{g}^{-1}$ of zeaxanthin. It is important to note that the lines (inbreds from Indian germplasm) had low concentration of $\beta$-carotene $\left(1.6 \mu \mathrm{g} \mathrm{g}^{-1}\right)$, whereas the testers (inbreds from CIMMYT-HarvestPlus maize programme) had high concentration $\left(11.3 \mu \mathrm{g} \mathrm{g}^{-1}\right)$ of the same. Kernel $\beta$-carotene concentration ranged from 1.6 to $6.2 \mu \mathrm{g} \mathrm{g}^{-1}$ with a mean of $3.8 \mu \mathrm{g} \mathrm{g}^{-1}$ among the crosses (Table 2). The study also revealed that the four commercial checks possessed much lesser $\beta$-carotene (mean: $1.8 \mu \mathrm{g} \mathrm{g}^{-1}$; range: 1.8 to $2.7 \mu \mathrm{g} \mathrm{g}^{-1}$ ) than the experimental hybrids. The proportion of different carotenoids among the genotypes with crtRB1 favourable allele (lines, testers and experimental hybrids) revealed that they possessed higher proportion of $\beta$-carotene $(36 \%)$ followed by zeaxanthin (35\%), lutein (22\%) and $\beta$-cryptoxanthin (7\%). In contrast, the commercial checks have higher proportion of non-provitamin A carotenoids, viz. zeaxanthin $(48 \%)$ and lutein $(31 \%)$; lesser proportion of $\beta$-carotene $(10 \%)$, while $\beta$-cryptoxanthin $(11 \%)$ remained almost same.

Correlation analysis was carried out to study the relationship among the different carotenoid components. Among the crtRB1-based genotypes lutein, zeaxanthin and $\beta$-cryptoxanthin were positively correlated among them $(r=0.67$ to 0.82$)$. However, $\beta$-carotene showed negative association with the other carotenoid components, viz. lutein 
Table 1. Combined ANOVA for combining ability of kernel carotenoids across two locations

\begin{tabular}{|c|c|c|c|c|c|}
\hline Sources of variation & df & Lutein & Zeaxanthin & $\begin{array}{c}\beta \text {-Crypto- } \\
\text { xanthin }\end{array}$ & $\beta$-Carotene \\
\hline Replication & 1 & $1.87 *$ & 0.01 & 0.04 & 0.20 \\
\hline Locations & 1 & $2.57 * *$ & 1.22 & 0.27 & 0.57 \\
\hline Replication $\times$ Location & 1 & 0.62 & 0.94 & 0.06 & 0.20 \\
\hline Crosses & 20 & $13.62 * *$ & $39.27 * *$ & $1.45 * *$ & $10.43 * *$ \\
\hline Line & 6 & $38.59 * *$ & $100.75 * *$ & $4.39 * *$ & $25.46 * *$ \\
\hline Tester & 2 & 1.68 & 23.94 & 0.06 & 3.70 \\
\hline Line $\times$ Tester & 12 & $3.12 * *$ & $11.08 * *$ & $0.22 *$ & $4.03 * *$ \\
\hline Location $\times$ Cross & 20 & 0.37 & 0.94 & 0.11 & $0.84 * *$ \\
\hline Location $\times$ Line & 6 & 0.21 & 0.37 & 0.07 & 0.38 \\
\hline Location $\times$ Tester & 2 & 0.90 & 0.09 & 0.15 & 0.86 \\
\hline Location $\times$ Line $\times$ Tester & 12 & 0.35 & 1.37 & 0.12 & $1.07 * *$ \\
\hline Error & 40 & 0.34 & 0.69 & 0.09 & 0.21 \\
\hline \multicolumn{6}{|l|}{ Components of variance } \\
\hline$\sigma_{\mathrm{gca}}^{2}$ & & 0.98 & 3.08 & 0.10 & 0.71 \\
\hline$\sigma_{\text {sca }}^{2}$ & & 0.68 & 2.61 & 0.03 & 0.95 \\
\hline $2 \sigma_{\mathrm{gca} /}^{2} \sigma_{\mathrm{sca}}^{2}$ & & 2.88 & 2.36 & 6.66 & 1.49 \\
\hline $\mathrm{h}^{2}{ }_{\mathrm{ns}}(\%)$ & & 70.97 & 66.73 & 73.85 & 48.74 \\
\hline
\end{tabular}

df - degrees of freedom; *, ** significance at $P \leq 0.05,0.01$, respectively; $\sigma_{\text {gca }}^{2}$ - general combining ability variance; $\sigma_{\text {sca }}^{2}-$ specific combining ability variance; $\mathrm{h}_{\text {ns }}^{2}-$ narrow sense heritability.

$(\mathrm{r}=-0.73)$, zeaxanthin $(\mathrm{r}=-0.62)$ and $\beta$-cryptoxanthin $(\mathrm{r}=-0.52)$. Grain yield did not show correlation with any of the carotenoid components, viz. lutein, zeaxanthin, $\beta$-cryptoxanthin and $\beta$-carotene.

The extent of fold change for lutein in experimental hybrids over commercial checks ranged from 0.61 to 1.37 across checks, while the same for zeaxanthin and $\beta$-cryptoxanthin were 0.60 to 1.85 and 0.57 to 0.73 , respectively. Among the experimental crosses, SE547× HP465-20 recorded highest fold increase of lutein and zeaxanthin, followed by SE547× HP467-4 and SE547 $\times$ HP467-9 over all the commercial checks used in the study. For $\beta$-carotene, majority of the experimental hybrids recorded higher $\beta$-carotene over all the commercial controls. The mean fold change for $\beta$-carotene over the checks ranged from 2.00 to 2.58 .

The study revealed the preponderance of additive gene action governing the accumulation of kernel carotenoids in maize. In majority of the crosses having desirable specific combining ability (SCA) effects for different carotenoids, either one or both the parents of the cross were having desirable general combining ability (GCA) effects (Tables 3 and 4). For example, in case of zeaxanthin, both the line (Pant125) and tester (HP467-9) showed significant GCA effects, while Pant $125 \times$ HP467-9 had significant SCA effects. 


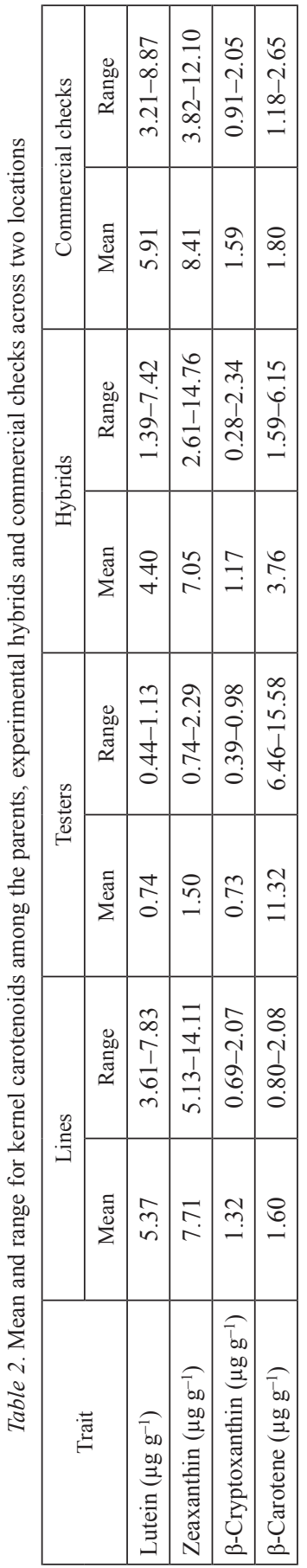

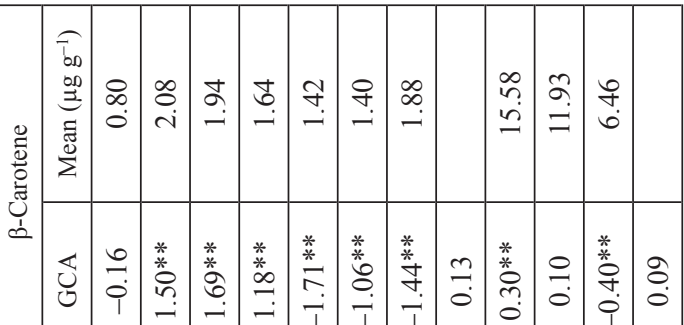

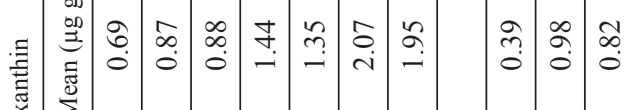

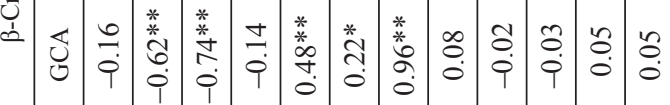

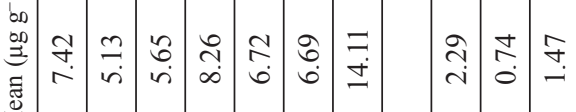

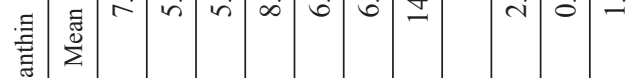

N

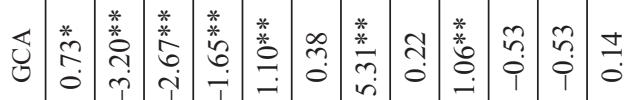

है

bo

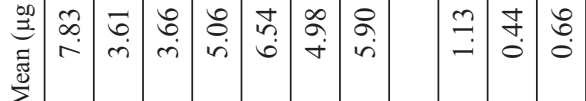

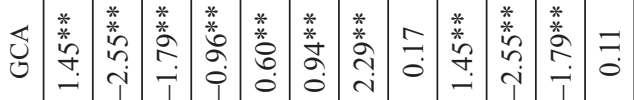

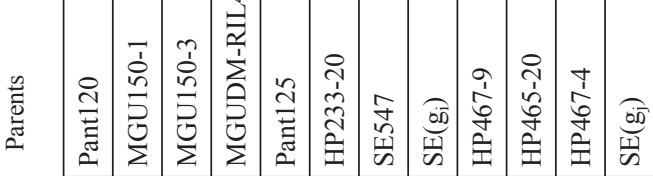

$\stackrel{\mathscr{\Xi}}{\exists}$ 


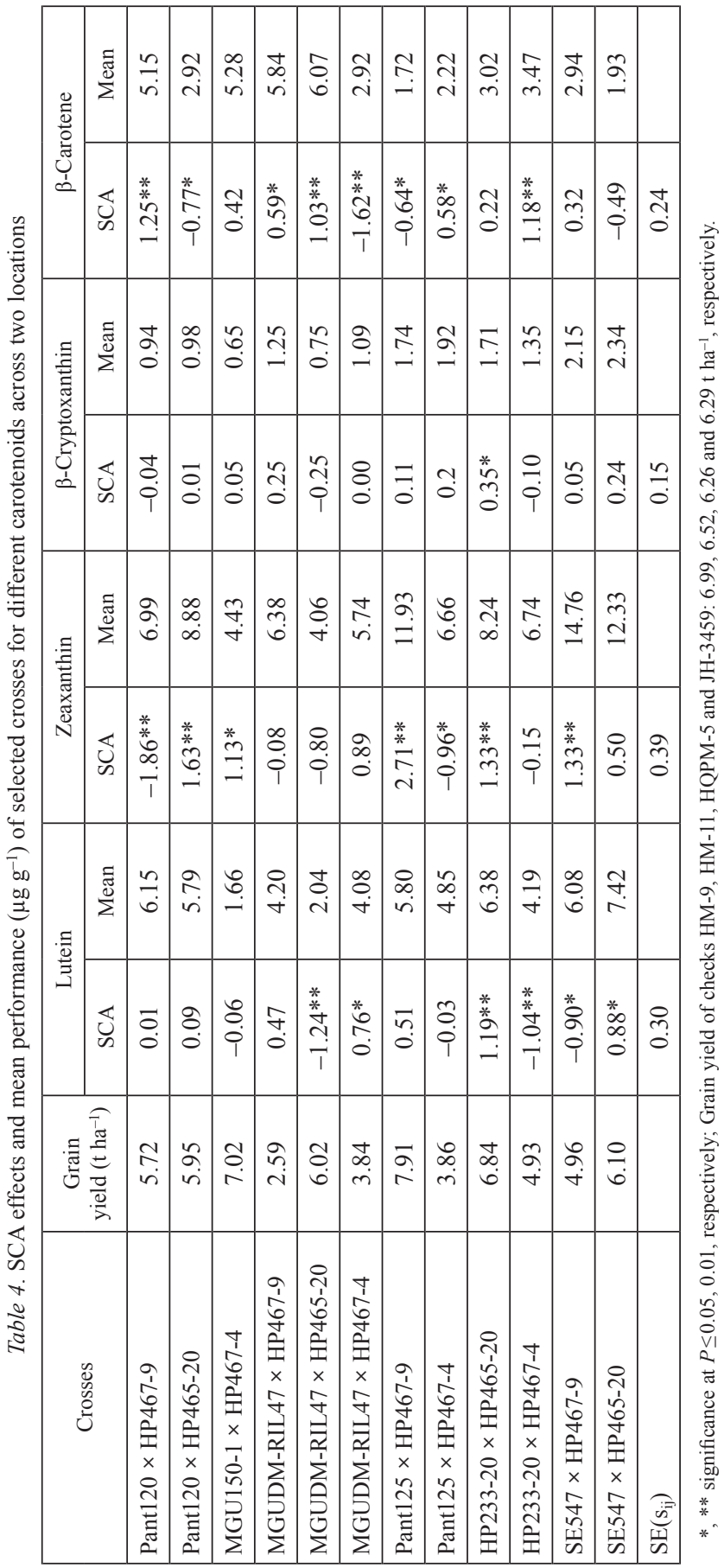


Similar observation was also observed in case of SE547 $\times$ HP467-9 (for zeaxanthin) and MGUDM-RIL47 $\times$ HP467-9 (for $\beta$-carotene). On the other hand, HP233-20 $\times$ HP465-20 showing desirable SCA effects for lutein and $\beta$-cryptoxanthin had significant GCA effects for line (HP233-20). Similarly, for $\beta$-carotene the tester (HP467-9) showed significant GCA effects for the cross Pant120 $\times$ HP467-9 (Tables 3 and 4).

Among inbreds, SE547, Pant120 and Pant125 were promising general combiners for non-provitamin A carotenoids, viz. lutein and zeaxanthin. SE547, Pant125 and HP233-20 emerged as the desirable general combiners for $\beta$-cryptoxanthin (Table 3 ). For $\beta$-carotene, MGU150-3 was observed to have the highest GCA effects followed by MGU150-1 and MGUDM-RIL47. Among the testers, HP467-9 was identified to have the highest GCA effects for both provitamin A ( $\beta$-carotene) and non-provitamin A (lutein and zeaxanthin) carotenoids (Table 3).

\section{Discussion}

The study revealed that carotenoid components, viz. lutein, zeaxanthin and $\beta$-cryptoxanthin are not sensitive to environmental conditions. Though $\beta$-carotene showed significant location $\times$ cross interaction, the proportion of sum of squares to total sum of square, was of quite low magnitude $(0.05 \%)$, thereby also suggesting that $\beta$-carotene is not much influenced by environments. Similar results of low effects of environment on carotenoid concentration have been observed in our earlier study while evaluating a set of 95 diverse inbred lines across three locations (Muthusamy et al. 2015a). Negligible effect of environment on kernel carotenoids was also reported in tropical inbred lines (Menkir et al. 2008), as well as temperate-inbreds (Kurilich and Juvik 1999) and hybrids (Egesel et al. 2003). The results, therefore, indicated that maize hybrids with enhanced carotenoids can be grown across the locations without much influence from environmental conditions. Medium to high heritability for the carotenoid components revealed in the study indicated that response to selection for these carotenoids in the breeding programme would be effective.

The study also revealed that significant variability exists for kernel carotenoids among the parents used in the study. The $\operatorname{crtRB} 1$ gene has been reported to be a major gene affecting two- to tenfold accumulation of $\beta$-carotene in maize kernel (Babu et al. 2013; Choudhary et al. 2014; Muthusamy et al. 2014). Though both the lines and testers possessed the favourable allele for crtRB1 3'TE gene which is known to cause higher accumulation of $\beta$-carotene, quite contrasting $\beta$-carotene concentration was observed between them. The favourable allele of $\operatorname{crtRB} 1$ gene was sequenced from a diverse set of inbreds varying for kernel $\beta$-carotene concentration, and nucleotide polymorphisms were identified that clearly differentiated the high and low $\beta$-carotene genotypes (Vignesh et al. 2013). These polymorphisms may be associated with the lower accumulation of kernel $\beta$-carotene, despite producing amplicon of favourable allele of the crtRB1 gene (Vignesh et al. 2013). The possible interaction of $\operatorname{crtRB} 1$ gene with other genes in the carotenoid biosynthesis pathway and/or with the background genome could also lead to difference in the concentration of $\beta$-carotene. 
Majority of the experimental crosses recorded almost similar lutein, zeaxanthin and $\beta$-cryptoxanthin than the commercial checks, but had $\beta$-carotene almost twice higher than checks (Table 2). Though, $\beta$-carotene level in the experimental hybrids was higher than the lines, it was much lesser as compared to testers. It is important to note that hybrids generated in the present study although were homozygous for the favourable allele of crtRB 1 gene, but alleles from both parents possibly differ in terms of nucleotide sequence, making the hybrid heterozygous for the allele. Babu et al. (2013) reported that favourable allele in homozygous condition is three times more effective than in the heterozygous condition for accumulating kernel $\beta$-carotene. Thus, the profound effects of allele from CIMMYT-HarvestPlus origin could have been possibly masked/affected by the allele from the Indian origin, which resulted in less $\beta$-carotene as compared to better parent. Thus, we hypothesize here that allele from CIMMYT-HarvestPlus origin should be in homozygous condition to reap the benefit of the allele effect. Considering this, markeraided introgression of this allele would be an effective strategy for provitamin A enrichment programme (Babu et al. 2013; Muthusamy et al. 2014).

Significant positive correlation among the carotenoids components except for $\beta$-carotene showed the possibility of simultaneous increase of all the above carotenoids. Negative correlation of $\beta$-carotene with other carotenoids revealed in the study could be due to genetic nature of the material used in the study, where all the genotypes possessed crtRB1 favourable allele, which blocks the conversion of $\beta$-carotene to further carotenoids in the pathway, viz. $\beta$-cryptoxanthin and zeaxanthin making them negatively correlated (Muthusamy et al. 2015a). Neutral association of carotenoids with grain yield offers possibility of enhancing kernel carotenoids in high yielding genotypes.

All the three potential hybrids with high lutein and zeaxanthin, viz. SE547 $\times$ HP46520, SE547 $\times$ HP467-4 and SE547 $\times$ HP467-9 have the inbred 'SE547' as a common parent, suggesting that SE547 could be used as one of the parents to develop hybrids with high non-provitamin A carotenoid, viz. lutein and zeaxanthin. These combinations would provide high antioxidants in the diet which would further reduce the risk of cardiovascular disease, one of the degenerative diseases in humans, worldwide (Olson 1989; Fraser and Bramley 2004; Dauchet et al. 2009). Besides, higher concentration of these carotenoids will increase the intensity of colour of the egg yolk (Hammershoj et al. 2010; Kljak et al. 2012). Further, consumers generally prefer yellow-orange egg yolk as compared to off-white yolk (Lokaewmanee et al. 2010; Liu et al. 2012) and poultry industry often utilize extracts from petals of marigold flower containing high xanthophylls like lutein and zeaxanthin as egg colorant in feed, as chicken has a natural ability to deposit these molecules into their egg yolks (Galobart et al. 2004; Lokaewmanee et al. 2010). Thus, hybrids with high lutein and zeaxanthin identified in the present study can be used specifically for poultry industry, the major consumer of maize production in Asia. Additionally, demand for maize in Asia is expected to increase rapidly over the next few decades, driven largely by the growing income and changing dietary habits (mainly increased poultry and pork consumption) that require more maize as feed (Prasanna et al. 2010).

The hybrid combination, MGU150-3 $\times$ HP465-20 was found to be the most promising for $\beta$-carotene, which showed more than 4-fold increase over HM-11 with an average of 
3.7-fold increase over all the checks. Similarly, the crosses, viz. MGUDM-RIL47 $\times$ HP465-20, MGUDM-RIL47 $\times$ HP467-9, MGU150-1 $\times$ HP467-9 and MGU150-3 $\times$ HP467-9 were identified as excellent combinations with higher concentration of $\beta$-carotene over the checks.

Preponderance of additive gene action than the non-additive action for carotenoids in maize was also reported in the earlier studies (Egesel et al. 2003; Senete et al. 2011; Suwarno et al. 2014). The predominance of additive gene action led to high to moderate narrow sense heritability for the kernel carotenoids. This suggests that improvement of kernel carotenoids would be quite fruitful through adopting population improvement approaches such as recurrent selection to develop promising inbred lines. It also suggested that predictability of generating promising cross combination would be high once genotypes with high concentration of carotenoid components are selected as parents. This is also evident from the fact that desirable SCA effects in majority of cross combinations is due to the one or both the parents having desirable GCA effects.

Inbred HP467-9, the CIMMYT-HarvestPlus genotype recorded high mean provitamin A at both the locations and will serve as potential donor for provitamin A enrichment in the Indian maize breeding programme. Based on SCA effects, SE547 $\times$ HP465-20, Pant125 $\times$ HP467-9, HP233-20 $\times$ HP465-20 and Pant120 $\times$ HP465-20 were identified as the best cross combination for non-provitamin A carotenoids and grain yield, implying that this combination can successfully be used as hybrid cultivar (Table 4). MGUDMRIL47 $\times$ HP465-20 and Pant120 $\times$ HP467-9 with desirable SCA effects and high grain yield potential emerged as most promising cross combinations for the maize provitamin A biofortification programme (Table 4). The promising experimental hybrids identified in the study are nutritionally more superior than the existing commercial hybrids, thus they can be exploited to alleviate degenerative diseases and VAD.

The present investigation led to the genetic dissection of kernel carotenoids in novel maize genotypes possessing rare genetic variation in the $\operatorname{crtRB} 1$ gene. The genotypes revealed wide variation for lutein, zeaxanthin, $\beta$-cryptoxanthin and $\beta$-carotene that were stable across environments. The preponderance of additive gene action was observed for all the carotenoid components warranting the need for involvement of both parents having desirable concentration of carotenoids. Promising high yielding experimental hybrids with high-non-provitamin A and -provitamin A carotenoids have been identified. These newly identified cross combinations hold promise in biofortification programme to enhance antioxidant- and provitamin A carotenoids in maize.

\section{Acknowledgements}

First author is grateful to Indian Council of Agricultural Research (ICAR) for the Senior Research Fellowship for his Ph.D. programme. This work was funded by Department of Biotechnology (DBT) under the project "Development of micronutrient-enriched maize through molecular breeding” (SAN No.102/IFD/SAN/4455/2011-2012). The authors sincerely acknowledge Dr. Kevin Pixley, CIMMYT-HarvestPlus maize programme for pro- 
viding $\beta$-carotene rich maize inbreds. We thank the breeders of GBPUAT, Pantnagar and PAU, Ludhiana for sharing their inbred lines.

\section{Conflict of Interest}

The authors declare no conflict of interest.

\section{References}

Babu, R., Rojas, N.P., Gao, S., Yan, J., Pixley, K. 2013. Validation of the effects of molecular marker polymorphisms in $l c y E$ and $c r t R B 1$ on provitamin A concentrations for 26 tropical maize populations. Theor. Appl. Genet. 126:389-399.

Bouis, H., Hotz, C., McClafferty, B., Meenakshi, J.V., Pfeiffer, W. 2011. Biofortification: A new tool to reduce micronutrient malnutrition. Food Nutr. Bull. 32:S31-S40.

Buckner, B., Kelson, T.L., Robertson, D.S. 1990. Cloning of the $y 1$ locus of maize, a gene involved in the biosynthesis of carotenoids. Plant Cell 2:867-876.

Burri, B.J. 1997. Beta-carotene and human health: A review of current research. Nutr. Res. 17:547-580.

Choudhary, M., Muthusamy, V., Hossain, F., Thirunavukkarasu, N., Pandey, N., Jha, S.K., Gupta, H.S. 2014. Characterization of $\beta$-carotene rich MAS-derived maize inbreds possessing rare genetic variation in $\beta$-carotene hydroxylase gene. Indian J. Genet. 74:620-623.

Choudhary, M., Hossain, F., Muthusamy, V., Thirunavukkarasu, N., Saha, S., Pandey, N., Jha, S.K., Gupta, H.S. 2015. Microsatellite marker-based genetic diversity analyses of novel maize inbreds possessing rare allele of $\beta$-carotene hydroxylase $(\operatorname{crtRB1})$ for their utilization in $\beta$-carotene enrichment. J. Plant Biochem. Biotechnol. 25:12-20.

Dauchet, L., Amouyel, P., Dallongeville, J. 2009. Fruits, vegetables and coronary heart disease. Nat. Rev. Cardiol. 6:599-608.

Egesel, C.O., Wong, J.C., Lambert, R.J., Rocheford, T.R. 2003. Combining ability of maize inbreds for carotenoids and tocopherols. Crop Sci. 43:818-823.

Fraser, B.D., Bramley, P.M. 2004. The biosynthesis and nutritional uses of carotenoids. Prog. Lipid Res. 43:228-265.

Galobart, J., Sala, R., Rincon-Carruyo, X., Manzanilla, E.G., Vila, B., Gasa, J. 2004. Egg yolk colour as affected by saponification of different natural pigmenting sources. J. Appl. Poult. Res. 13:328-334.

Gupta, H.S., Hossain, F., Muthusamy, V. 2015. Biofortification of maize: An Indian perspective. Indian J. Genet. 75:1-22.

Hammershoj, M., Kidmose, U., Steenfeldt, S. 2010. Deposition of carotenoids in egg yolk by short-term supplement of coloured carrot (Daucus carota) varieties as forage material for egg-laying hens. J. Sci. Food Agri. 90:1163-1171.

Kljak, K., Drdic, M., Karolyi, D., Grbesa, D. 2012: Pigmentation efficiency of Croatian corn hybrids in egg production. Croatian J. Food Tech. Biotechnol. Nutr. 7:23-27.

Kurilich, A., Juvik, J.A. 1999. Quantification of carotenoid and tocopherol antioxidants in Zea mays. J. Agri. Food Chem. 47:1948-1955.

Liu, Y.Q., Davis, C.R., Schmaelzle, S.T., Rocheford, T., Cook, M.E., Tanumihardjo, S.A. 2012. $\beta$-Cryptoxanthin biofortified maize (Zea mays) increases $\beta$-cryptoxanthin concentration and enhances the color of chicken egg yolk. Poult Sci. 91:432-438.

Lokaewmanee, K., Yamauchi, K., Tsutomu, K., Saito, K. 2010. Effects on egg yolk color of paprika or paprika combined with marigold flower extracts. Italian J. Anim. Sci. 9:356-359.

Menkir, A., Liu, W., White, W.S., Maziya-Dixon, B., Rocheford, T. 2008. Carotenoid diversity in tropicaladapted yellow maize inbred lines. Food Chem. 109:521-529. 
Muthusamy, V., Hossain, F., Thirunavukkarasu, N., Choudhary, M., Saha, S., Bhat, J.S., Prasanna, B.M., Gupta, H.S. 2014. Development of $\beta$-carotene rich maize hybrids through marker-assisted introgression of $\beta$-carotene hydroxylase allele. PLoS One 9:e113583

Muthusamy, V., Hossain, F., Thirunavukkarasu, N., Saha, S., Agrawal, P.K., Gupta, H.S. 2015a. Genetic variability and inter-relationship of kernel carotenoids among indigenous and exotic maize (Zea mays L.) inbreds. Cereal Res. Commun. 43:567-578.

Muthusamy, V., Hossain, F., Thirunavukkarasu, N., Pandey, N., Vishwakarma, A.K., Saha, S., Gupta, H.S. 2015b. Molecular characterization of exotic and indigenous maize inbreds for biofortification with kernel carotenoids. Food Biotechnol. 29:276-295.

Muthusamy, V., Hossain, F., Thirunavukkarasu, N., Saha, S., Gupta, H.S. 2015c. Allelic variations for lycopene $\varepsilon$-cyclase and $\beta$-carotene hydroxylase genes in maize inbreds and their utilization in $\beta$-carotene enrichment programme. Cogent Food and Agric. 1:1033141.

Olson, J.A. 1989. Biological actions of carotenoids. J. Nutr. 119:94-95.

Prasanna, B.M., Pixley, K.V., Warburton, M., Xie, C. 2010. Molecular marker-assisted breeding for maize improvement in Asia. Mol. Breed. 26:339-356.

Senete, C.T., Guimaraes, P.E.D., Paes, M.C.D., Souza, J.C. 2011. Diallel analysis of maize inbred lines for carotenoids and grain yield. Euphytica 182:395-404.

Suwarno, W.B., Pixley, K.V., Palacios-Rojas, N., Kaeppler, S.M., Babu, R. 2014. Formation of heterotic groups and understanding genetic effects in provitamin A biofortified maize breeding program. Crop Sci. 54:14-24.

Vignesh, M., Hossain, F., Nepolean, T., Saha, S., Agrawal, P.K., Guleria, S.K., Prasanna, B.M., Gupta, H.S. 2012. Genetic variability for kernel $\beta$-carotene and utilization of crtRB1 3'TE gene for biofortification in maize (Zea mays L.). Indian J. Genet. 72:189-194.

Vignesh, M., Nepolean, T., Hossain, F., Singh, A.K., Gupta, H.S. 2013. Sequence variation in 3'UTR region of crtRB1 gene and its effect on $\beta$-carotene accumulation in maize kernel. J. Plant Biochem. Biotechnol. 22:401-408.

Yan, J., Kandianis, B.C., Harjes, E.C., Bai, L., Kim, H.E., Yang, X., Skinner, D.J., Fu, Z., Mitchell, S., Li, Q., Fernandez, S.M., Zaharoeva, M., Babu, R., Fu, Y., Palacios, N., Li, J., DellaPenna, D., Brutnell, T., Buckler, S.E., Warburton, L.M., Rocheford, T. 2010. Rare genetic variation at Zea mays crtRB1 increases $\beta$-carotene in maize grain. Nat. Genet. 42:322-329.

Zunjare, R., Hossain, F., Muthusamy, V., Jha, S.K., Kumar, P., Sekhar, J.C., Guleria, S.K., Singh, N.K., Nepolean, T., Gupta, H.S. 2015. Genetics of resistance to stored grain weevil (Sitophilus oryzae L.) in maize. Cogent Food Agric. 1:1075934. 